\title{
AN OPERATIONAL DEFINITION OF DAY TRIPS: \\ METHODOLOGICAL PROPOSAL AND APPLICATION TO THE CASE OF THE PROVINCE OF BARCELONA
}

\author{
Jordi Suriñach ${ }^{1}$, \\ Josep A. Casanovas², \\ Marién André1, \\ Joaquim Murillo ${ }^{1}$, \\ Javier Romaní ${ }^{1}$
}

1 AQR-IREA Research Group. University of Barcelona. Facultat Economia I Empresa.

Diagonal 690. jsurinach@ub.edu (corresponding author, Phone: +34934020545; Fax:

+34934021821, http://orcid.org/0000-0003-2622-3280); andre@ub.edu;

j.murillo@ub.edu; romani@ub.edu; Jordi Suriñach wants to acknowledge ECO2016-75805-

$\mathrm{R}$, from the Spanish Ministry, and all authors the support received from Diputació de Barcelona.

2 Cegos-Consultur. jacasanovas@cegos.es Gran Vía Carles III, 85 Bis. 08028 Barcelona 


\title{
AN OPERATIONAL DEFINITION OF DAY TRIPS: \\ METHODOLOGICAL PROPOSAL AND APPLICATION TO THE CASE OF THE PROVINCE OF BARCELONA
}

\begin{abstract}
The day tripper (or day visitor) is a visitor type that represents a high proportion of total visitor trips; however, unlike, the tourist, few studies focus their attention specifically on them. Additionally, there is currently a marked deficit of methodological specificity in the definition of the concept and the quantification procedures used in its study. This article examines the various definitions proposed to date of the "day trip", highlighting this lack of specificity, above all with regard to the concept of usual environment. It then proposes a specific methodology for the quantification of day trips in small areas, without discounting official statistics, but seeking to make it independent of other variables (including the size of a territory). We propose linking usual environment with belonging to the same urban system. The article concludes by applying our proposal to the case of the province of Barcelona.
\end{abstract}

Keyword: Day trips, Tourism, Usual environment, quantification, Province of Barcelona 


\section{Introduction}

Tourism, a complex phenomenon comprising the activities of persons travelling to places outside their usual environment for leisure, business or other purposes (UNWTO, 2010a), has proven global socio-economic importance (Daberlay and Stock, 2012) and generates significant direct, indirect and induced impacts on the economy (WTTC/Oxford Economics, 2013; Murillo et al, 2013).

Among the many types of tourism, same-day trips (or day trips) represent a high proportion of trips; yet, paradoxically, the number of studies dedicated to the analysis of day trippers are few, especially compared to tourists in general. The main reason for this general omission is related to the difficulty in defining and delimiting the phenomenon. The fact that day trippers do not stay overnight in their destination hinders their quantification, characterization and analysis. Tourists, in contrast, stay overnight at the destination, making use of tourist accommodation, so they can be much more easily identified. As a result, most of the tourist literature has focused on their study.

The analysis of day trippers is further hindered by the fact that most demand-side studies concern themselves with international tourist movements (although the volume of domestic tourism is greater than foreign tourism) and while day trips involving a border-crossing are recorded, they represent a very small percentage of visitors coming from abroad (with the obvious exception of border towns). Consequently, these visitors are usually ignored in the literature.

The situation is further exacerbated by the ambiguity in the definitions provided of tourism. For example, when defining the phenomenon, the United Nations World Tourism Organization (UNWTO) specifies that the length of the trip cannot exceed a 
year and that the purpose of the trip should not be related to the exercise of an activity remunerated from within the place visited. Additionally, in relation to the places visited, the definition merely states that persons should find themselves outside their "usual environment". This expression - at first sight relatively straightforward - gives rise to major difficulties because, while the other conditions associated with the definition are standard and readily identifiable for the majority of visitors, the usual environment can only be seen as being unique to each individual and one, moreover, that can change over time. As such, the usual environment becomes the subject of specific analyses in order to determine whether the travellers can be considered as tourism travellers (tourists or day trippers), or whether they need to be included within a different category of traveller.

However, while the phenomenon of day trips has been addressed in the literature (see next Section for a review), what is missing is a consensual definition that can be applied to all types of territory regardless of their size. This is actually a critical issue, especially for tourism management. With the increasing figures of travellers, some destinations are suffering of an excessive pressure on them. Carrying capacity is being overpassed, with environmental, social and economical struggling as result. Some cities are experiencing the phenomenon of over tourism, so conflict between residents and visitors have emerged (Ashworth and Page, 2011). Nevertheless, how can destinations manage tourism if they do not have real and complete figures? ${ }^{3}$

Hence, the aim of this article is to devise an operational definition for day trips, above all one that is applicable to small areas (municipalities and groups of municipalities),

3 For instance, in the city of Barcelona studies (see Murillo et al, 2013) calculate that there are at least one day tripper for every tourist sleeping in the town. 
and one that clarifies what a day tripper is and is not in any given territory. In other words, this article seeks to develop an operational definition of day trips which, while respecting international recommendations, should clarify the current uncertainty surrounding the concept. Our proposal involves first developing a definition of day trips for a simple administrative unit (specifically, the municipality) and then extending this definition to facilitate the calculation of day trippers in any larger area. In addition, the article applies this theoretical framework to the province of Barcelona (Catalonia, Spain). It must be said that in Suriñach et al (2017) a first approach to the concept of usual environment is presented, in order to apply it in all developments carried out. The current paper focuses in methodology, deepening in this concept involved in the wider topic of day tripping, under the fact that there remain more questions than answers involving the usual environment concept.

Our approach to the study of day trips adheres to international recommendations concerning the methodology for analysing tourism and related concepts as drawn up by UNWTO, the Organisation for Economic Cooperation and Development and Eurostat. These recommendations are contained in three main documents: International Recommendations on Tourism Statistics (henceforth, IRTS -2008, UNWTO, 2010), International Recommendations for Tourism Statistics 2008. Draft Compilation Guide (henceforth, IRTS: CG-2008; UNWTO, 2011) and the Tourism Satellite Account: Recommended Methodological Framework (henceforth, TSA: RMF-2008; UNWTO et al., 2010b). One of our main concerns in providing a definition of day tripper is delimiting the concept of usual environment, which the UNWTO explicitly leaves open, but on the understanding that each of these statistical organizations should make 
explicit the criteria they use in order to ensure comparability and the correct interpretation of the data.

To achieve the goals outlined above, the second section undertakes a comprehensive review of the literature examining the criteria used in defining the concept of usual environment. This review highlights major discrepancies in the operational definition used when calculating day trippers. The third section develops an operational definition of day tripper and the usual environment. The fourth section outlines the terminology, variables and geographical factors required to define and characterize day trippers in the province of Barcelona. The last section concludes.

\section{The usual environment. State of the art}

The usual environment and the difficulty in establishing a universal criterion of identification. A review of the literature and international definitions

Tourists are persons that travel to a destination outside their usual environment and who stay in this place for less than a year for leisure, business, or other purposes. The tourist does not exercise any activity for which he or she is remunerated at the place visited.

Bearing this definition in mind, the concept of usual environment plays a key role in distinguishing a visitor (a tourist/day tripper) from other travellers. Indeed, this concept is specific to tourism statistics (not being used in either a country's balance of payments or its national accounts). The purpose of introducing the concept of usual environment is to exclude from the category of visitors those people that regularly travel from their place of residence to their place of work or study, or who are frequent visitors of given places in the course of their daily life. Therefore, the criterion applied is the frequency with which the trip is made, not distance (UNWTO, 2011). 
The concept of usual environment acquires strategic importance in estimates of the number of visitors. Just what constitutes the usual environment can be determined in two ways: using either exogenous or endogenous methods (Govers et al., 2008). The former require the researcher to obtain data about travellers (place of usual residence, place of work or study and other frequently visited places) and their trips (frequency, distance, etc.) while the latter allows the travellers themselves to define their usual environment.

If we take as our starting point the guidelines established in IRTS-2008 (UNWTO, 2010a, 2011) and those provided for in the TSA: RMF-2008 (UNWTO, 2010b), we find that "Some countries leave it to the respondent to decide whether a trip taken qualifies as a tourism trip [the endogenous method]. However, in order to ensure comparability between responses within the country and over time, it is recommended that national statistical offices, tourism authorities and/or other organizations with direct responsibility for tourism statistics be encouraged to establish national criteria to operationalize the concept of usual environment". Furthermore, "Because the measurement of flows of visitors and of all associated variables is highly sensitive to the definition of the usual environment, it is further recommended that neighbouring countries or countries belonging to supranational organizations consult with each other in order to ensure compilation of comparable statistics."

The UNWTO (2010) notes that there are often differences between countries in terms of population density, transportation accessibility, cultural behaviours, proximity to administrative or national borders, etc. that hinder the establishment of a unique, universally valid, statistical determination of the usual environment of an individual person. However, it is recommended that the determination of the usual environment 
be based on the following criteria: (a) the frequency of the trip (b) the duration of the trip, (c) the act of crossing a national or administrative border, and (d) the distance travelled.

According to UNWTO (2011), these last two criteria (border crossings and distance) should be used because: (a) administrative units may be of very different sizes even within the same country, (b) metropolitan areas may stretch over other administrative boundaries, and (c) the place of usual residence of some individuals might be located very close to the administrative borders, so that such crossings might not mean their leaving their usual environment.

In short, the recommendations of UNWTO (2010b) are that national statistical offices should establish the limits of the usual environment, in statistical terms, depending on the distance travelled, frequency of visits, and the crossing of administrative borders, but, bearing in mind that the usual environment hosts the regular movements of people, it is recommended that each country determines the precise meaning of what is considered habitual and frequent in the context of their tourism statistics.

A review of various methodological documents provided by national statistical offices confirms that, different operational definitions are applied in defining what is considered as the travellers' usual environment. This is clearly illustrated if we observe the selection of variables (criteria) and the statistical thresholds established for these same criteria (see Table 2.1).

(TABLE 2.1 around HERE)

The World Travel and Tourism Council (WTTC, 2013) also uses the concept of usual environment in its definition of visitor so as to exclude those who commute daily between their residence and place of work or study, or other frequently visited places. 
However, the WTCC argues that a definition of usual environment based on distance, duration and location alone has several limitations. To overcome these problems, the Council believes that the definition of tourist travel should avoid using these strict criteria, and allow the traveller to explain what lies "beyond the usual environment" using, where possible, statistical approaches to define the usual environment. This perspective means that travellers subjectively determine their usual environment (WTTC - Oxford Economics, 2013).

Yu et al. (2012) compare the distances on which the operational definitions of usual environment are made with the propensity to self-categorise as tourists and find that the propensity is positively related to the distance travelled and first-visit status. However, from a sociological perspective, Usher (2002) shows that there is no linear relationship between usual environment and geographical distance.

Eurostat $(2010,2014)$ adheres to the same definition of usual environment as that forwarded in IRTS-2008 (UNWTO, 2010a): that is, the geographical area, though not necessarily a contiguous one, within which a person carries out his regular life routines. This territory is determined on the basis of the following criteria: the crossing of administrative borders or the distance from the place of usual residence, and the duration, purpose and frequency of the visit. However, Eurostat (2014) ultimately recommends leaving the interpretation of the usual environment to the subjective opinion of the respondent and encourages him or her to respond spontaneously (thus contradicting UNWTO proposals), using the following criteria:

(a) The purpose of the visit, in other words, whether or not the trip is part of the regular life routines of the traveller. If we take the guidelines of IRTS- 2008 as our reference, the definition of visitors should not include travellers that 
commute between their usual place of residence and place of study or work, or those who frequently visit places in the context of their everyday life routine.

(b) Crossing of administrative boundaries (borders). Eurostat proposes the use of administrative territorial units (ATU) at the municipal level, to identify both day trippers and tourists. This criterion seeks to exclude from consideration as tourist travel all movements that occur within a municipality (assuming that the municipality is part of the usual environment). The boundaries of the municipality are an objective element and can be readily understood by respondents ${ }^{4}$. However, in its manual of methodology for tourism statistics, Eurostat (2014) suggest that the criterion of distance ${ }^{5}$ might be used as an auxiliary criterion to help reduce any grey areas that may appear when using the criterion of the crossing of administrative boundaries.

(c) Duration of the visit. Eurostat recommends establishing a minimum duration for the visit, in order to exclude day trips that are too short to include an element of tourism. This recommendation is in line with IRTS-2008 (UNWTO, 2010a). The minimum duration recommended is three hours.

(d) Frequency of the visit. Eurostat (2014) recommends that it should be less than once a week. A journey that is repeated every week is considered to be

\footnotetext{
4 However, in some cases the municipality boundary can be an ambiguous concept (Eurostat, 2014). For example, when two neighbouring municipalities constitute a continuous centre.

5 This must be expressed in units of physical distance (IRTS-2008); (UNWTO, 2010a). The size of their usual environment may depend on the type of activity concerned. While the regular shopping routines can be expected to take place within a maximum distance of 10 kilometers around the place of residence, other regular activities (e.g., a weekly sports match) can take place further away from their place of residence (for example, in the nearest city), which could not be part of the administrative border of their municipality.
} 
performed in the usual environment and, therefore, should not be considered tourism.

Although Eurostat has sought to reach a consensus among its Member States concerning the operational definition and criteria to identify a person's usual environment, their efforts have been unsuccessful and they have failed to establish a common theoretical framework (Eurostat, 2014). Eurostat (2009) highlights the differences in the guidelines and criteria used to define usual environment in the EU Member States.

Thus, the definition and measurement of tourism, despite official guidelines, remain too open to interpretation. Thus, in order to establish a clear definition, it is needed to identify operational criteria that are specific, clear, and consistent with the principles discussed up to this juncture in the article, taking as our reference IRTS-2008 (UNWTO, 2010a-2011) and its adaptation by the EU (Eurostat, 2014).

\section{Operational definition of usual environment and day trips.}

We next present a methodological proposal to define an individual's usual environment and a day trip. We review the main arguments in support of the operational decision selected and consider the methodological limitations of the proposal.

\section{Basic definitions. The starting point}

Usual environment is defined as the geographical area, though not necessarily a contiguous one, within which a person carries out his/her regular life routines. Specifically, the European Tourism Regulation (UE) 692/2011 defines usual environment in rule 2.1.e: 'usual environment' means the geographical area, though not necessarily a contiguous one, within which an individual conducts his regular life routines and shall 
be determined on the basis of the following criteria: the crossing of administrative borders or the distance from the place of usual residence, the duration of the visit, the frequency of the visit, and the purpose of the visit.

In line with UNWTO's basic definitions (2008), we consider a day tripper to be a visitor who leaves his destination without having stayed overnight, the destination cannot form part of the individual's usual environment, and the motivation of the visit can be any (business, leisure, cultural, religious, etc.) as long as it does not entail the receipt of any remuneration from a resident company or entity.

The usual environment and analysis of local day trips: an operational definition From the above definitions, the concept of usual environment is clearly established; however, what remains vague is how the spatial limits should be fixed when considering whether or not an individual is within their usual environment, given that any definition of day trip is conditioned by the practical definition of usual environment (Wynen, 2013; Smith, 1999).

The endogenous approach discussed in section 2 above introduces a high degree of subjectivity, with the same individual liable to give different responses depending on the time, mood, etc. To avoid this, we need to find ways to define a person's usual environment with the greatest precision possible using rigorous and reliable methodology. Thus, in determining whether an individual is located within or outside their usual environment, we need to consider territorial criteria and the trip frequency, which we can consider objective criteria. Therefore our contribution is the development of an operational definition of the usual environment which is based in clear, homogeneous and objective criteria that can be implemented in any territory. 
The criteria for usual environment have been applied very unevenly: many countries use distance criteria (for example, a radius of 40 kilometers from home, in the case of Canada), but this uniform criterion ignores the specific characteristics of each area (including density, roads, public transport, availability of private vehicles, etc.), or alternatively travel time (for example, a radius centered on a three-hour journey). Increasingly, administrative units (Arkenford Ltd., 2008) are being used as the criterion for defining usual environment. But, is the municipality the correct territorial unit in this case? The literature raises concerns about the demographic and geographical differences between territories. For this reason, in certain cases, alternative data (i.e., journey duration and/or distance) have also to be used, in spite of the existence of well-defined administrative regions (such as the municipality). The reasons underpinning such a decision are the existence of administrative units of different sizes; the presence of metropolitan areas that extend beyond an administrative border; and, the fact that some individuals might reside in areas close to an administrative border. Several countries consider the municipality as constituting the usual environment (see Table 2.1), but clearly the average size of the municipalities in each country needs to be taken into account. For example, the average size of Swedish municipalities is 1,552 km²; $896 \mathrm{~km}^{2}$ in Norway; $420 \mathrm{~km}^{2}$ in Denmark, and $299 \mathrm{~km}^{2}$ in Portugal. These values are large enough to consider that a trip to another municipality may not be usual. But in other European countries, like Spain $\left(62 \mathrm{~km}^{2}\right)$, Italy $\left(37 \mathrm{~km}^{2}\right)$, Germany $\left(30 \mathrm{~km}^{2}\right)$, and France $\left(18 \mathrm{~km}^{2}\right)$ the average size of the municipalities is much smaller. In the case of the province of Barcelona it is $25 \mathrm{~km}^{2}$. This means that the average person can walk across an average Spanish municipality in less than two hours, and, in the case of 
Barcelona, in less than an hour. Obviously, in the case of the inhabitants of the province of Barcelona, their usual environment exceeds the municipality boundaries.

Thus, in order to provide a definition of day trips, we first need to find an appropriate definition of an individual's usual environment. As no overnight trips fit into the categories of day trips or commuting, we believe that the usual environment can be defined in terms of the regularity of the commute.

Our proposal relates usual environment with the individual's urban system (see CasadoDiaz and Coombes, 2011). From a spatial perspective, we define zones (generally, groups of municipalities) that constitute what are known as functional areas, that is, areas of daily displacement (or "daily urban systems"), areas of labour mobility (or "travel-to-work areas"), commercial areas, etc. (see Casado, 2000; Feria et al, 2015). The idea underpinning these concepts is a territorial division into a number of areas, each of which is recognized by its residents as constituting their usual environment. Therefore, the resident living in one of these areas can perform all the activities of their daily life without leaving it. Most methodologies ensure that the division of the territory is exhaustive (i.e., all the municipalities belong to one urban system) and univocal (i.e., each municipality can only belong to one urban system) ${ }^{6}$.

If we conclude, therefore, that for the vast majority of people these urban systems correspond to their usual environment, this simplifies the question as to whether a trip is an example of commuting or a day trip: a trip within a single urban system can be considered commuting, while a trip between two urban systems can be considered a

6 Note, however, that in our methodological proposal, the relationships not univocal. A municipality can belong to more than one urban system. 
day trip. Thus, although the ideal definition of usual environment remains open to debate, commuting can be used to build an operational definition.

Opinions also differ regarding trip frequency: although the week is the temporal unit most used, some countries employ alternative criteria (for example, more than ten times per quarter). There is an additional difficulty with frequency, namely that trip frequency can vary depending on the time of year or even the year itself.

As shown in Table 3.1, only in the event that both the geographical area and the trip frequency are not usual can we talk of day trips.

\section{(TABLE 3.1 around HERE)}

This article, therefore, considers the "urban system" concept as an alternative to administrative criteria. As such, its contribution is that in order to define the day trippers within a given municipality, we must first define the urban system of the origin municipality so that the travellers who go outside this system can be considered day trippers (provided they spend less than 24 hours there, they do not stay overnight, they travel there less than once a week and they do not seek to exercise any remunerated activity once there).

The change in approach with regard to previous studies is that in order to define a day trip to municipality $M$, we must first identify the urban system associated with it so as to eliminate the trips that might be made from other municipalities (,$B$ or $C$ ) for whom $\mathrm{M}$ is a part of theirs usual environment. These trips will not therefore be considered day trips because they constitute habitual trips (see Figure 3.1).

\section{(FIGURE 3.1 around HERE)}

M's day trippers are all the individuals that travel there minus those who travel there habitually, i.e., those for whom $\mathrm{M}$ lies within their usual environment. Thus, if we take 
municipality $A$ (or $B$ or $C$ ), if the number of people travelling from $A$ (or $B$ or $C$ ) to $M$ is high then we consider $\mathrm{M}$ to form part of the usual environment of $\mathrm{A}$ (or $\mathrm{B}$ or $\mathrm{C}$ ).

Therefore, individuals travelling to $M$ from $A, B$ and $C$ cannot be considered as day trippers, given that $M$ is part of the usual system of the three municipalities. However, individuals travelling from a municipality such as $D$ (or $E$ ), for which $M$ does not constitute part of their usual environment, will be considered day trippers.

In short, to determine the number of day trippers visiting $M$, we must first determine the urban systems of the origin municipalities, i.e., the set of neighbouring municipalities (in this case, $A, B$ and $C$ ) from which $M$ attracts a significant number of regular visitors. Since these movements are habitual, they cannot be considered to constitute day trips. Thus, $\mathrm{M}$ can be considered to form part of the usual environment of $A, B$ and $C$ and as such, $A, B$ and $C$ form part of M's urban system.

If we want to calculate the number of day trips to area $C_{A}$, we first have to analyze the day trips to all the municipalities in the area and then sum the total number of day trippers. Imagine we wish to determine the number of day trippers to municipality number 1 (see Figure 3.2), represented with a white circle and lying in urban system 1 (US1). The day trips to municipality 1 are made up of all the movements of individuals that live outside US1 and who spend less than 24 hours there, do not stay overnight and do not have as their goal a remunerated activity in the destination (and who travel there less than once a week). The same can be said for municipalities 2 and 3 in relation to their respective urban systems (US2 and US3).

(FIGURE 3.2 around HERE) 
Thus, the day trippers in area $C_{A}$ are all those corresponding to each municipality in $C_{A}$. Note that the boundaries of these three urban systems overlap in some cases (see Figure 3.2).

Figure 3.3 shows the type of journeys that should be considered day trips for the three municipalities lying within area $\mathrm{C}_{\mathrm{A}}$. They include inter- and intra-area movements, but in no circumstances is a movement from within the same urban system considered a day trip. For example, a journey from a municipality in another area $\left(C_{B}\right)$ to a municipality in $\mathrm{C}_{\mathrm{A}}$ will be considered to be a day trip if the former does not belong to the same urban system as the latter; however, if this municipality lies in the same urban system then it will not be considered a day trip.

(FIGURE 3.3 around HERE)

Local day trips: a practical approach to day trips in the province of Barcelona How then might the criteria and recommendations outlined above be applied? As we show below there are many complex situations in which we need to determine whether an individual should be considered a day tripper or another type of traveller. For example:

a. The reason for taking the trip does not affect the classification, except in the case of those who undertake a remunerated activity at the destination. Those who travel to a destination frequently - the journey becoming a habitual activity should not be considered day trippers. Thus, it is not the reason underlying the journey, rather it is the space within which it occurs and the frequency with which it occurs, that should determine its classification. 
Example 1: A person who visits their family (or lives to play sport) in another town (or urban system) once a week would not be considered a day tripper, but if we do that every fortnight, they will be considered a day tripper. What has to be considered is whether the individual is within a usual "space" according to the specific settings, without taking into consideration the motive for the journey.

b. The municipality (or urban system) is the smallest unit of a person's usual environment. Journeys within this municipality (or urban system) will never be considered as a day trip, even though the visit is made to an unusual environment.

Example 2: If someone that lives in Barcelona visits the Park Güell for the first time and has no plan of returning there in years, even though the park is some way from their home, they will not be considered as being a day tripper.

c. The distance criterion does not determine the classification.

Example 3: Business travellers that have to travel from Barcelona to Madrid $(600 \mathrm{~km})$ once a week are excluded from the day tripper category on the grounds of frequency (the distance criterion not being a determinant).

d. A second residence constitutes an exceptional case. A trip to a second residence is considered a tourist trip; thus, all the activities carried out during this stay will be considered as tourism. If the individual is staying at their second residence, or making trips from this base, the activities will be classified as tourism (if staying overnight) or as a day trip (if not staying overnight). A visit to the second residence will only be considered as constituting the usual environment (and therefore not considered as a day trip) when the individual visits the residence more than once a week. However, due 
to the special characteristics of this case, we propose that this population be counted separately from other tourists and day trippers, under a heading "Population counted separately" or "Second residence day trippers".

Example 4: If someone visits their second residence to celebrate a special event, or to do some home reforms, and the visit is less than 24 hours in duration, it is considered a day trip. But If someone visits their second residence and stays less than 24 hours, but does so more than once a week, then the trip is considered to be in their usual environment and, therefore, is not considered a day trip.

e. Visits undertaken by tourists that do not start from their place of usual residence, but from the place where they have stayed overnight are considered tourist visits. However, visits undertaken by tourists in a different municipality from that in which they stayed overnight are considered as day trips ${ }^{7}$. It should be borne in mind that the concept of usual environment applies to resident but not to non-resident tourists.

Example 7: If a tourist is spending the night in Barcelona but spends the day at the Benedictine Abbey of Montserrat ${ }^{8}$, the activity will be considered a day trip.

\section{Urban systems and habitual mobility. The case of the province of Barcelona}

The province of Barcelona (indicated in white), located in the region of Catalonia (indicated in green), lying in the north-east of the Iberian Peninsula, occupies an area of

\footnotetext{
7 Here we need to take into consideration the specific case of overnight visitors in an urban continuum such as "Metropolitan Barcelona" (Barcelona, Sant Adrià, L'Hospitalet, etc.). Tourists that spend the night in hotels located in these municipalities are day trippers, but could be considered "tourists" of Barcelona, given that there is no discontinuity in the urban space and given their own perception of being tourists in Barcelona.
}

8 At a distance of $50 \mathrm{~km}$ from Barcelona. 
$7,726.36 \mathrm{~km}^{2}$ (see Figure 4.1). The province has 311 municipalities distributed among eleven $\operatorname{comarcas}^{9}$ (or counties) (see Table 4.1).

(FIGURE 4.1 around HERE)

(TABLE 4.1 around HERE)

We next show how to characterize the concepts of the urban systems and the usual environment for the specific case of the province of Barcelona, in order to quantify the number of day trippers in the province. It is important to remark that this methodology is not only applicable to metropolitan areas such as Barcelona, but it can still be extrapolated to all kind of small areas, whenever there is a territorial plot with identifiable nuclei and infrastructures of connection between them. In this sense it is applicable, for instance, to study day tripping to, for instance, monuments, sites, or for rural areas, and it will mainly depend on available and suitable statistics.

\section{Information sources}

To define the urban systems, we draw on the 2011 Population Census (which provides details regarding journeys to work and study) plus various mobility surveys conducted in the province of Barcelona. These include the Weekday Mobility Survey (EMEF) conducted by the Metropolitan Transportation Authority (henceforth, EMT), but it does not cover all the municipalities in the province. In 2006, however, the survey was also conducted in a more exhaustive fashion and with a larger sample (Everyday Mobility Survey-EMQ). The Metropolitan Area of Barcelona (AMB) ${ }^{10}$ conducts a complementary

9 A comarca is an administrative territorial unit of Catalonia, lower than NUTS 3 territorial division. It is a particularity within the territorial division in Spain, which is divided into Autonomous Communities (regions), as well as those are then divided into provinces. However, in the case of Catalonia, there are also these smaller units, comarcas, similar to the idea of counties, with a capital and with a Council ruling them.

10 The $A M B$ includes 36 municipalities from the province of Barcelona and 59\% of its population. 
survey in the municipalities of the first metropolitan ring. These two surveys, although not as exhaustive as the Census of Population, record more reasons for citizen mobility than does the Census ${ }^{11}$.

Statistical information used to define the header municipalities (see following subsection) include data taken from the Anuario Económico de España (Economic Yearbook of Spain - La Caixa and Instituto LR Klein, 2013) and from the Anuario de la Distribución en España (the Yearbook of Distribution in Spain - Indisa, 2013). These data provide variable information for municipalities with more than 1000 inhabitants (see Table 4.2).

(TABLE 4.2 around HERE)

Finally, the Pla de marketing i I'Inventari de Productes Turístics de la Província de Barcelona (Marketing Plan Tourism Product Inventory of the Province of Barcelona the Barcelona Provincial Council, 2012) provide information about the main tourist attractions of the municipalities and allow us to select the municipalities capable of attracting visitors (including day trippers).

Defining header municipalities

In order to calculate day trippers in the Province of Barcelona, the first step is to define the urban systems so that we can identify trips that occur outside a person's usual environment (i.e., those that can potentially be considered day trips).

As outlined in previous section, we first need to identify the urban system associated with each municipality so as to eliminate all journeys to it originating in the usual environment of the resident. We consider each municipality as a center of its own urban system and the municipalities most closely linked to it for reasons of mobility. 
However, the inclusion of a municipality (K) as part of the usual environment of municipality $M$ does not prevent $K$ from belonging to the usual environment of other municipalities (A, B, C, etc.). For each municipality, its usual environment is constructed using mobility flows provided by data from the 2011 Census of Population, the Weekday Mobility Survey (EMEF) and the Everyday Mobility Survey (EMQ), and the Mobility Survey of the First Metropolitan Ring (2011).

This methodology presents two practical problems when applied to an area that is larger than a municipality: first, if we want to calculate the percentage of day trips undertaken in a relatively large area (such as the 311 municipalities making up the province of Barcelona), the construction of the usual environment can be a very laborious operation. Moreover, given the characteristics of some of the sources of information on mobility flows (EMEF and EMQ), flows between many of the smaller municipalities are not yet known, or are subject to sampling errors ${ }^{12}$.

To solve these two problems, we propose pre-defining the municipalities that can be considered potential centers (or header municipalities) for the movements of day trippers. The usual environment then can be built just for these municipalities. For example, in region $C_{A}$ (see Figure 3.2), we would calculate the percentage of day trips in just three municipalities (1,2 and 3$)$, defining for each the three associated urban systems.

Thus, we have to select the municipalities with the greatest commercial, leisure (including restaurants) and tourism potential, and which serve as centers of attraction for day trippers. To do so, we use the Economic Yearbook of Spain, the Yearbook of

12 This problem does not arise with the Population Census, but information from this source is older (2011) and only considers trips related to work and study 
Distribution in Spain and the Marketing Plan of the Province of Barcelona and the Tourism Product Inventory. We select as header municipalities those that group a significant proportion of a comarca's total of the above concepts, accounting for much of the comarcal mean or having a high number of inhabitants.

In Table 4.3. we illustrate the potential centres obtained by selecting the municipalities that account for more than $10 \%$ of their comarca's total for each of the key variables listed in Table 4.2, and with more than 10,000 inhabitants. For example, if we take the 26 municipalities of Alt Penedès, two (Vilafranca and Sant Sadurní d'Anoia) have more than 10,000 inhabitants. Likewise, two account for more than $10 \%$ of the total retail trade in the comarca (the comarca had 1,406 retail establishments in 2012 , but only Sant Sadurní [13\%] and Vilafranca [58\%] had more than 10\%), and so on for the rest of the variables and comarcas considered. With this information, we can then determine, for each comarca, the municipalities with the greatest capacity to attract visitors, i.e., our potential centres or header municipalities.

(TABLE 4.3 around HERE)

Table 4.4 presents the analysis, by way of example, for the comarca of Alt Penedès. Here, an " $X$ " indicates the municipalities that are considered "headers" (in order to calculate both weekday and weekend day trippers). This procedure is repeated for all the comarcas in the province.

(TABLE 4.4 around HERE)

\section{Definition of urban systems}

Once a header municipality has been identified (M), we need to identify the municipalities linked to it by strong flows of usual mobility and which can be considered as forming part of its usual environment. To do this, we draw on the data 
described in subsection 4.1, specifically the mobility databases (EMT and AMB surveys and the Population Census). This step is performed using only intermunicipal flows. The surveys outlined above provide mobility flows between $M$ and the other Catalan municipalities (A, B, C, etc.).

Although these flows are bidirectional, we are interested in only one. If we consider the municipalities $M$ and $A$, there are two flows between them: $M \rightarrow A$ and $A \rightarrow M$; however, given that we only need to determine the number of visitors to municipality $M$, we are only concerned with the second of these flows. Therefore, our data of interest for constructing the usual environment of municipality $M$ are flows $A \rightarrow M$; $B$ $\rightarrow M ; C \rightarrow M ; D \rightarrow M$; etc. Yet, of these flows, we use only those that are large enough to indicate, unequivocally, a strong relationship between the two municipalities. As a threshold, we choose a flow that represents at least $4.5 \%$ of the total displacements originating from municipality $A$, or at least $4.5 \%$ of the total flows received by municipality M. Therefore, all municipalities with a flow of mobility towards municipality $M$ that fulfills one of these two conditions are considered part of municipality M’s usual environment.

An additional problem emerges when the city of Barcelona, or another major municipality in the metropolitan area, presents a high ratio of mobility with the municipality whose usual environment we are seeking to delimit. While this relationship is not usually spurious, the question arises: Which of the two municipalities is part of the usual environment of the other? Generally, the flow from the municipality under analysis towards Barcelona is more important, in percentage terms, than the reverse flow: for example, Barcelona is part of the usual environment of the residents of Vilafranca, but not vice versa. This means that when a Barcelona 
resident visits Vilafranca, they travel outside of their usual environment. For this reason, when a municipality that does not form part of the Metropolitan Area of Barcelona has an important relationship of mobility with Barcelona (or with another town near Barcelona, but some distance from the rest of its usual environment), we opted not to include Barcelona in their normal environment.

Our methodology does not explicitly require the geographical contiguity of all the municipalities that make up the usual environment of a header.

Maps 4.1 to 4.8 show the urban systems of the comarca of Alt Penedès. The municipalities that form part of the usual environment of each header municipality in this comarca are shown. Thus, the movements in each header municipality that meet the criteria defined in section 3.2 (travellers from outside the urban system, when the stay is of a duration of less than 24 hours, does not include an overnight stay, conducted with a frequency of less than once a week and there is no intention of carrying out a remunerated activity on arrival) are considered to be day trips.

(MAPS 4.1 to 4.8 around HERE)

Once the usual environments (or urban systems) associated with each header municipality have been defined, the next step is to quantify the number of day trips to each of these municipalities. The quantification of a larger area (for example, the whole comarca of Alt Penedès) can then be calculated by summing the number of day trips to each header municipality within the wider comarca.

\section{Final summary}

The day trip is a key phenomenon in any analysis of tourism, because of the significant number of movements generated and their consequent impact on planning issues, on 
broader supply questions within the sector and on tourism expenditure in general. However, the literature and the majority of studies opt to focus on tourists alone and so ignore day trippers.

The day trip is basically a local phenomenon, which hinders the collection of data, mainly because day trippers do not stay overnight at their destination and owing to several reasons for undertaking such visits (not all of which can be quantified as day trips).

This article summarises current understanding of the concept of the day trip, and it proposes an operational definition, focusing specifically on one of the most important but least discussed aspects of that definition, namely, a person's usual environment. The concept of usual environment is undoubtedly the key element for studying flows of tourists and day trippers at the local level, and although it has generated considerable debate, it has yet to be defined satisfactorily.

This article has sought to adhere to the guidelines proposed by various international organizations in proposing a definition and methodology for determining the movements that can be classed as day trips, based on the characterisation of the usual environment and its operationalization in what we refer to as an urban system.

This proposal has the advantage of being valid for any level of analysis: urban systems can be calculated for a single municipality or for a group of municipalities, and from there extrapolated to the level of a county, province or region.

In this sense, an advantage of methodology presented is that functional divisions of the territory, based in the daily home-to-work trips of individual workers, have been in use for a long time in many countries as an economic and social planning tool. The paper proves that this instrument can be improved by using also other usual (daily or weekly) 
trips, like shopping or leisure trips. As long as the information about these trips exists and is available to local authorities, methodology to design the usual environment for a given town or city can easily be replicated.

Thus, here, the operational definition proposed for the day trip is a displacement with a duration of less than 24 hours that is made outside an individual's urban system of residence at a frequency of less than once a week, there being no intention on their part of exercising an activity that will be remunerated at that place on arrival.

As such, the concept of usual environment is defined in terms of the "urban system". Movements within a single urban system are considered as constituting usual mobility, while movements between two systems can be considered an urban day trip.

The article also forwards an operational proposal for analyzing the phenomenon of the day trip at a level above that of the municipality (i.e., at the local or regional level). Given the obvious difficulties of analysing the day trips to all the constituent municipalities (basically owing to a lack of statistical information), when translating theoretical frame into empirical application, this research makes some assumptions that have been explained. These assumptions work for the case of analysis; nevertheless, further research on them in the future should be of interest in order to test their applicability to all cases. The first propose is to focus the study on certain municipalities (that is, potential centres or header municipalities) which are defined on the basis of a set of criteria or indicators, including their tourist and leisure attractions, demographic variables and commercial and economic activity.

A second proposal in this article concerns the sources from which the urban system for each municipality can be built. We propose working exclusively with interurban mobility flows, which means relying on mobility surveys and establishing a number of 
specific criteria. Thus, a municipality that has a mobility flow towards a particular header municipality fulfilling pre-established conditions, is considered part of its usual environment. Thus, this approach allows us to determine just what is and what is not a day trip, by excluding movements to a municipality from other municipalities that belong to its sphere of influence, whether they belong to the same comarca or not.

The article has shown how this operational definition of the usual environment, urban system and day trip can be applied to the specific case of the comarca of Alt Penedès in the province of Barcelona. Moreover, the aim of this paper to settle a definition and methodology applicable to different kind of areas has been fulfilled. Research presented can be applied to territories with a structure based on urbanized nodes, whatever their type or dimension. Methodology may be extrapolated to both urban and rural environments, as well as theoretical discussion can be applied to define the usual environment both for rural zones as well as urban areas, helping to clarify the territorial limits, and some other conditions, to distinguish between visitors from usual travelers. Nevertheless, the paper is based in availability of proper statistical data bases; actually this point emerges as a key issue for the application of current findings to other areas and cases. Finally, results also show that the presence of a major attractor (big city, important tourist resource,...) may distort results, so specificities must be regarded. As a consequence, further research in non-urban settings would be of interest, in order to improve and spread findings applicability and application.

\section{Bibliography}

AMB (2011): Enquesta de Mobilitat a la Primera Corona Metropolitana. http://xarxamobal.diba.cat/XGMSV/cat/indicadors/indicadors_emt1.asp 
Ashworth, G.; S.J. Page (2011): "Urban tourism research: Recent progress and current paradoxes." Tourism Management, Volume 32, Issue 1, pp. 1-15

Canadian Travel Commission -CTC- i Instituto de Estudios Turísticos -IET- (2003) "Research on National Practices Defining the Normal Environment: Basic Findings." Enzo Paci Papers, vol.3. World Tourism Organization. Disponible online: http//www.unwto.org/statistics/material/normalenv.pdf

Casado-Díaz, J.M.; Coombes, M. (2011): “The delineation of 21st century local labour market areas: a critical review and a research agenda". Boletín de la Asociación de Geógrafos españoles, no51, pp 7-32.

Casado-Díaz, J.M. (2000): "Local labour market areas in Spain: a case study". Regional Studies, 34 (9), pp. 843-856.

Diputació de Barcelona (2012) Província de Barcelona.Pla de Marqueting turístic. www.diba.cat

Entitat Metropolitana del Transport (2012): Enquesta de Mobilitat en Dia Feiner. http://www.iermb.uab.es/htm/mobilitat/cat/emef.asp

Entitat Metropolitana del Transport (2006): Enquesta de Mobilitat Quotidiana. http://www.iermb.uab.es/htm/mobilitat/cat/emq.asp

ETR/FAMILITUR (2016). Encuesta de Turismo de Residentes. Metodología. INE.

Eurostat (2009) Tourism Satellite Accounts in the European Union. Volume 1: Report on the implementation of TSA in 27 EU Member States. Methodologies and working papers. European Communities.

Eurostat (2010) Tourism Satellite Accounts (TSA) in Europe. Eurostat Methodologies and Working Papers. Luxembourg: Office for Official Publications of the European Communities.

Eurostat (2014) Methodological manual for tourism statistics - 2014, v. 3.1. Collection: Manuals and guidelines. European Union.

Feria, J.M.; J.M. Casado-Díaz, L. Martínez-Bernabéu (2015): "Inside the metropolis: the articulation of Spanish metropolitan areas into local labor markets." Urban Geography, 36 (7), pp. 1018-1041.

Govers, R.; Van Hecke, E. and Cabus, P. (2008) "Delineating Tourism. Defining the normal enviroment." Annals of Tourism Research, 35, 4, pp.1053-1079.

La Caixa (2013). Anuario Económico de España 2013. www.lacaixa.es/estudios. Colección Estudios y Análisis Económico.

Murillo, J.; Vayá, E.; Romaní, J; Suriñach, J (2013): “How Important to a City are Tourists and DayTrippers? The Economic Impact of Tourism on the City of Barcelona." Tourism Economics, Vol 19(4), pp. $897-917$.

Smith, S.L.J. (1999): "How far is far enough? Operationalizing the concept of «usual environment» in tourism definitions." Tourism Analysis, Vol 4(3-4), pp. 137-143(7). 
Suriñach, J.; Casanovas, J.; André, M.; Murillo, J.; Romaní, J. (2017): "How to quantify and characterize day trippers at the local level: An application to the comarca of the Alt Penedès". Tourism Economics, Vol 23(2), pp. 360-386.

UNWTO -United Nations \& World Tourism Organization- (2010a) International Recommendations for tourism statistcs. United Nations Publication, ST/ESA/STAT/SER.M/83/Rev.1. Disponible online a: http://unstats.un.org/unsd/statcom/doc08/BG-TourismStats.pdf

UNWTO (World Tourism Organisation and United Nations), Comission of European Communities, Organisation for Economic Cooperation and Developmet (2010b). Tourism Satellite Account: Recommended Methodological Framework. United Nations Publication, ST/ESA/STAT/SER.F/80/Rev.1. Disponible online a: http://www.oecd.org/document/27/0,3343,en $2649343891883547 \quad 1 \quad 1 \quad 1$ 1,00.html

UNWTO (2011) International Recommendations for Tourism Statistics 2008. Draft Compilation Guide. Statistics and Tourism Satellite Account Programme. Madrid, March 2011

Usher, R. (2002) "Putting Space Back on the Map: Globalisation, Place and Identity." Educational Philosophy and Theory, 34(1): pp.41-55.

Wynen, J. (2013): “Explaining travel distance during same-day visits." Tourism Management, Vol. 36, pp. 133-140.

WTTC/Oxford Economics (2013) Travel \& Tourism Economic Impact Methodology. Oxford Economics. World Travel and Tourism Council (WTTC)

Yu, X.; Kim, N.; Chen, Ch. and Schwartz, Z. (2012) "Are You a Tourist? Tourism Definition From the Tourist Perspective." Tourism Analysis, Vol. 17(4), pp. 445-457. 
Table 2.1. Criteria used in different countries to delimit the usual environment (overnight trips)

\begin{tabular}{|c|c|c|c|}
\hline Country & Distance Definition & Frequency Definition & Other Definition \\
\hline Australia & $40 \mathrm{~km}$ in one direction & & \\
\hline Bolivia & $\begin{array}{l}\text { Duration: } 4 \text { hours (one } \\
\text { direction) }\end{array}$ & & \\
\hline Brazil & & Regularly & \\
\hline Canada & $80 \mathrm{~km}$ in one direction & & \\
\hline Chile & $30 \mathrm{~km}$ in one direction & Weekly & \\
\hline China & ATU (Province or city) & & \\
\hline Costa Rica & & & Usual environment \\
\hline Czech Republic & ATU (City, village) & 2 times per week & \\
\hline Ecuador & ATU (Municipality) & Not defined & \\
\hline Egypt & ATU (Governance) & Not defined & \\
\hline Finland & $30-50 \mathrm{~km}$ in one direction & Weekly & \\
\hline France & & & Respondent definition \\
\hline Holland & & & $\begin{array}{l}\text { Vacation purpose and } \\
\text { duration }\end{array}$ \\
\hline Italy & ATU (Municipality) & Weekly & \\
\hline Malta & ATU (Isle) & Regularly & Purpose \\
\hline Mexico & ATU (Policy-admin. division) & Not defined & \\
\hline Morocco & ATU (City) & & \\
\hline New Zealand & $40 \mathrm{~km}$ in one direction & & \\
\hline Oman & ATU (State) & 18 trips per year & \\
\hline Panama & Not defined & & \\
\hline Philippines & & & Usual environment \\
\hline Portugal & & Weekly & \\
\hline Slovenia & $25 \mathrm{~km} \& 24 \mathrm{~h}$ away from home & 10 times a quarter & Respondent definition \\
\hline Spain & ATU (Municipality) & & \\
\hline Sweden & $40 \mathrm{~km}$ in one direction & & \\
\hline Switzerland & & Weekly & \\
\hline Thailand & ATU (Municipality) & & \\
\hline United Kingdom & & & All overnight trips \\
\hline Uruguay & ATU (Location) & & \\
\hline Venezuela & ATU (Municipality) & & \\
\hline
\end{tabular}

Source: The Canadian Tourism Commission and Instituto de Estudios Turísticos (2003). Note: ATU: Administrative Territorial Unit.

Table 3.1.

\begin{tabular}{|l|l|c|c|}
\cline { 3 - 4 } \multicolumn{2}{c|}{} & \multicolumn{2}{c|}{ Frequency } \\
\cline { 2 - 4 } & Habitual & Usual environment & Usual environment \\
\hline \multirow{3}{*}{ Geographical Area } & Not habitual & Usual environment & Day Trips \\
\cline { 2 - 4 } & &
\end{tabular}

Source: Own elaboration 
Figure 3.1. Urban System of Municipality M

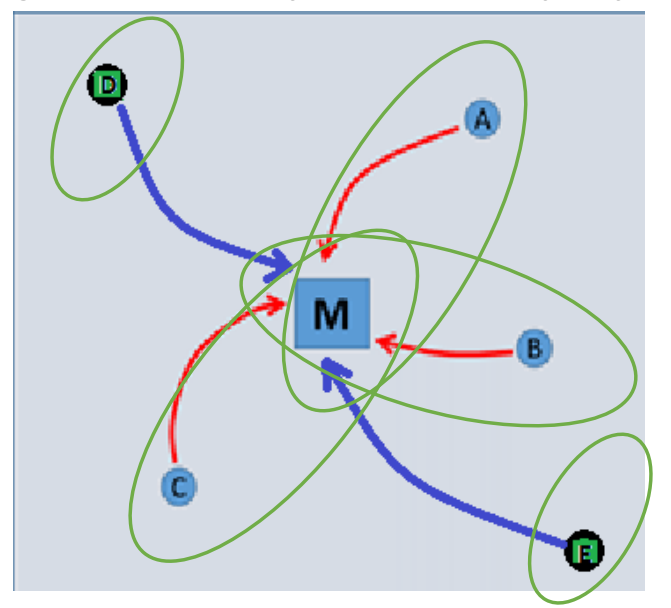

--- No day trips ---- Day trips _ Urban system of municipality A, B, C, D and E 


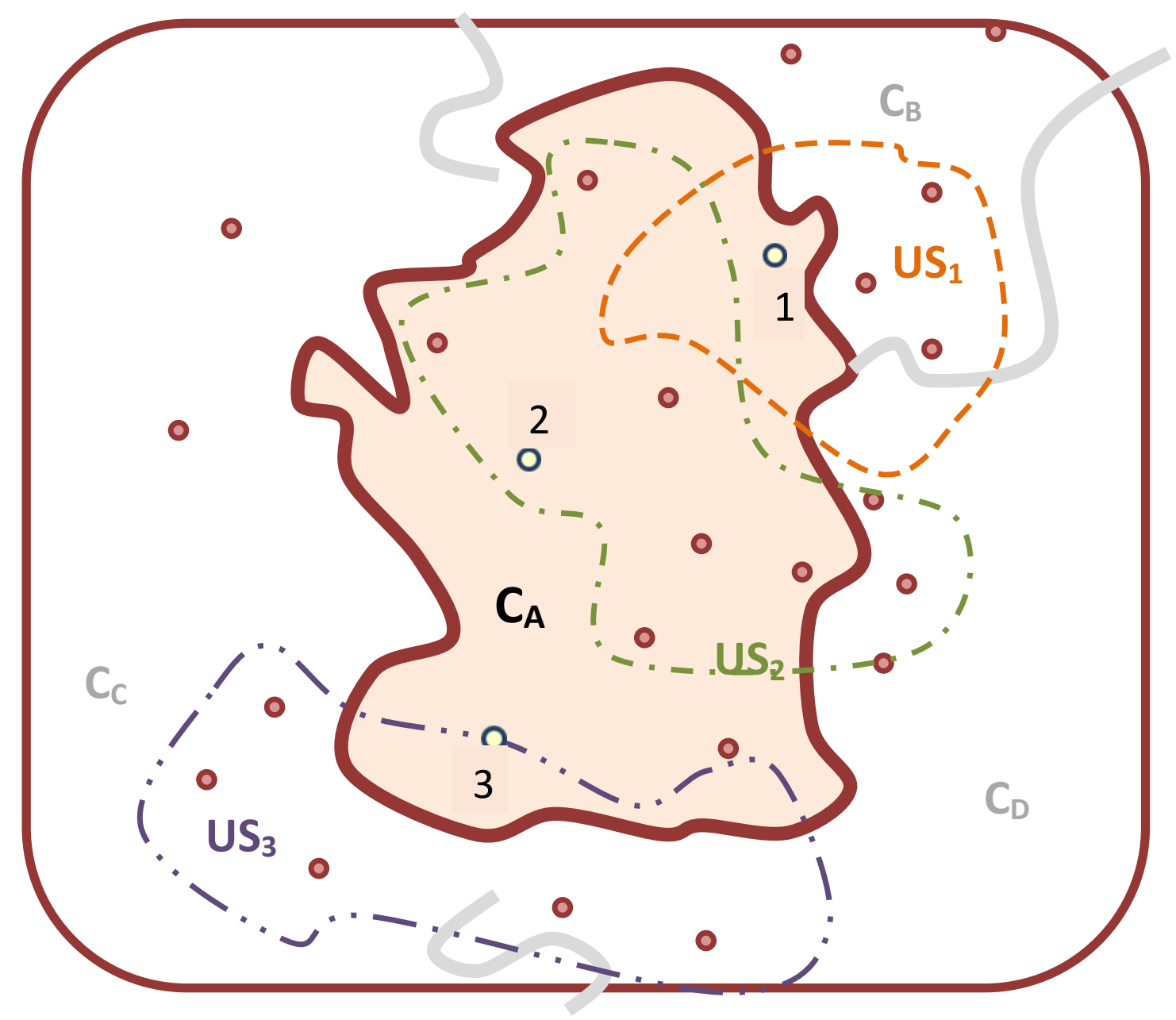

\begin{tabular}{|l|l|}
\hline Symbol & Meaning \\
\hline $\mathbf{O}$ & Municipalities in the area \\
\hline $\mathbf{O}$ & Head municipalities in an urban system \\
\hline & Pilot analysed area $\left(\mathrm{C}_{\mathrm{A}}\right)$ \\
\hline & Areas adjacent to $\mathrm{C}_{\mathrm{A}}$ \\
\hline & \\
\hline
\end{tabular}

\begin{tabular}{|l|l|}
\hline Symbol & Meaning \\
\hline & Limits US 1 \\
\hline & Limits US 2 \\
\hline & $\begin{array}{l}\text { Administrative limits of the } \\
\text { area }\end{array}$ \\
\hline
\end{tabular}

Source: Own elaboration 


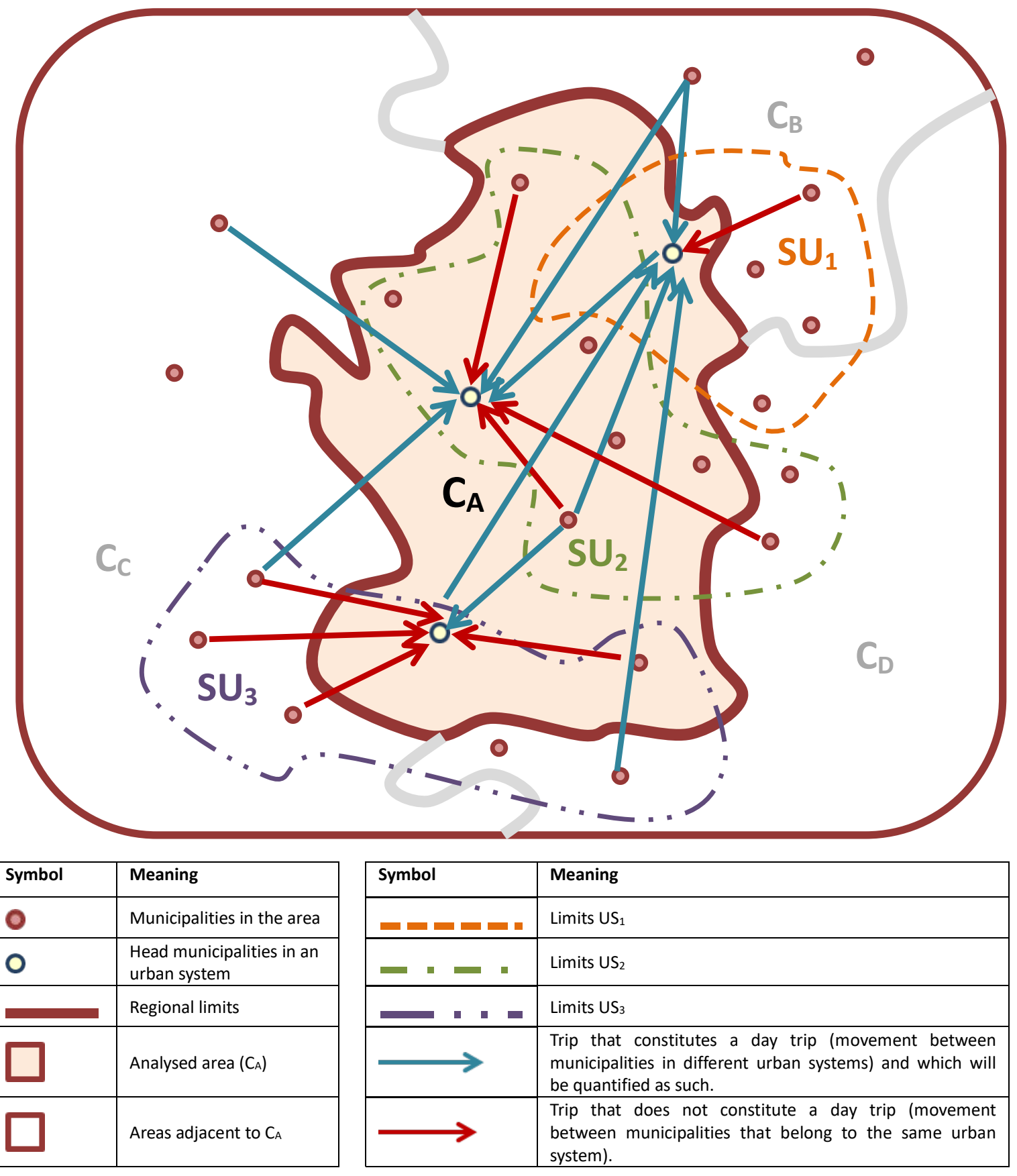

Source: Own elaboration 
Figure 4.1. Administrative boundaries, municipal and for comarcas in the province of Barcelona

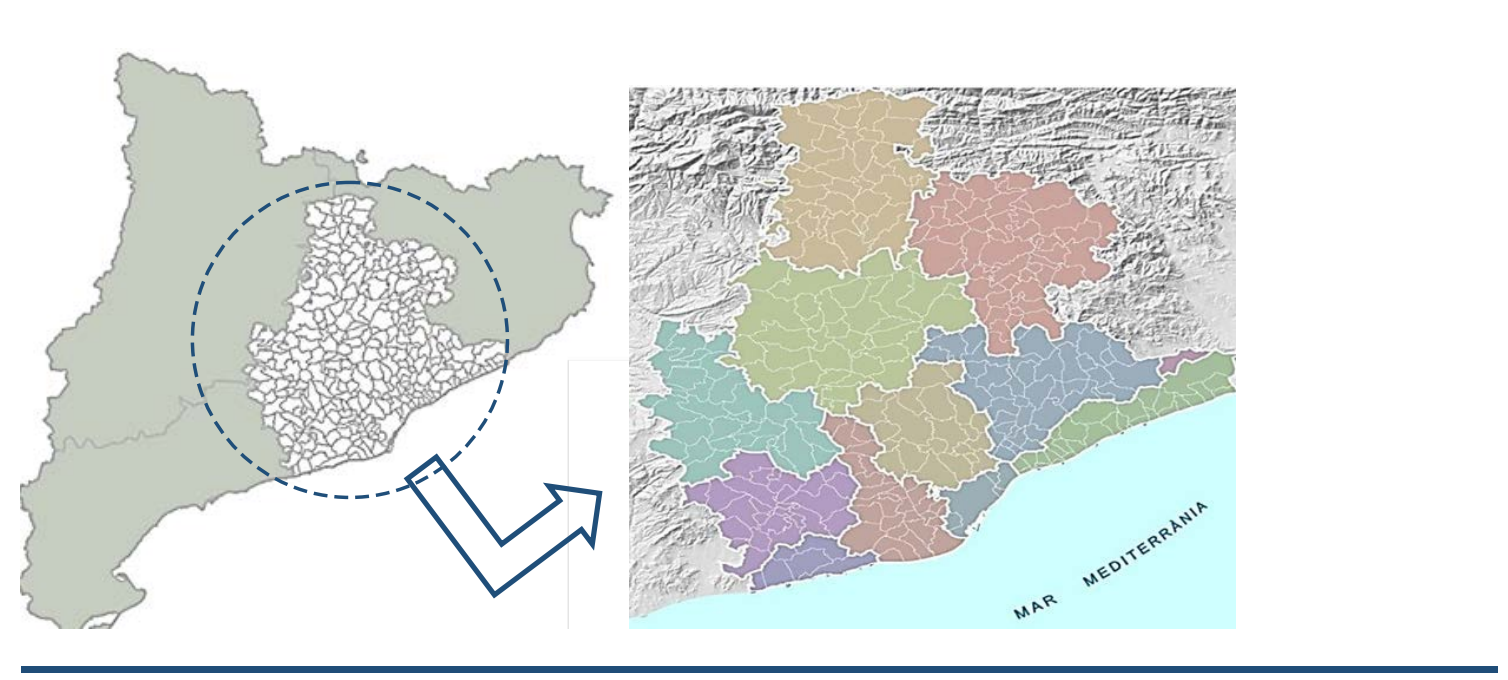

Source: Own elaboration 
Table 4.1. Comarcas within Barcelona's Province

\begin{tabular}{lrc}
\hline Comarca & \multicolumn{1}{c}{$\mathbf{k m}^{\mathbf{2}}$} & Municipalities \\
\hline Alt Penedès & 592,69 & 27 \\
Anoia & 866,31 & 33 \\
Bages & $1.299,09$ & 35 \\
\hline Baix Llobregat & 485,99 & 30 \\
\hline Barcelonès & 145,75 & 5 \\
\hline Berguedà & $1.128,96$ & 30 \\
Garraf & 185,11 & 6 \\
Maresme & 398,53 & 30 \\
\hline Osona & $1.157,70$ & 48 \\
\hline Selva & 32,12 & 1 \\
Vallès Occidental & 583,13 & 23 \\
Vallès Oriental & 850,98 & 43 \\
\hline Barcelona Province & $\mathbf{7 . 7 2 6 , 3 6}$ & 311 \\
\hline
\end{tabular}

Source: DIBA (Diputació de Barcelona)

Table 4.2. Variables used to define head municipalities

Market share of the municipality in 2012

Number of bank offices in 2013

Number of business premises in industry and construction

Number of commercial wholesale premises

Number of commercial retail premises 2012

Surface $\left(\mathrm{m}^{2}\right)$ of commercial retail premises

Shopping malls

Surface $\left(\mathrm{m}^{2}\right)$ of shopping malls, 2012

Number of restaurants and bars

Wholesale trade index
Retail sales index

Index of restaurants and bars

Tourist index

Economic activity index

Number of Cash \& Carry establishments

Total surface Cash \& Carry $\left(\mathrm{m}^{2}\right)$

Number of hypermarkets

Total surface of hypermarkets $\left(\mathrm{m}^{2}\right)$

Number of hypermarkets of more than $1000 \mathrm{~m}^{2}$

Total surface of hypermarkets of more than $1000 \mathrm{~m}^{2}$

Source: Economic Yearbook of Spain and Yearbook of Distribution in Spain. 
Table 4.3 Number of municipalities that have more than $10 \%$ of comarca total for each item

\begin{tabular}{|c|c|c|c|c|c|c|c|c|c|c|c|c|c|c|c|c|c|c|}
\hline Comarcas & $\begin{array}{c}\text { Total } \\
\text { municipa- } \\
\text { lities }\end{array}$ & $\begin{array}{c}\text { More } \\
\text { than } \\
10,000 \\
\text { resident } \\
\text { s }\end{array}$ & $\begin{array}{l}\text { Market } \\
\text { share }\end{array}$ & $\begin{array}{c}\text { Bank } \\
\text { offices }\end{array}$ & $\begin{array}{c}\text { Commerci } \\
\text { al retail } \\
\text { premises }\end{array}$ & $\begin{array}{l}\text { Surface } \\
\text { of } \\
\text { commer } \\
\text { cial } \\
\text { retail } \\
\text { premise } \\
\text { s }\end{array}$ & $\begin{array}{c}\text { Shopping } \\
\text { malls }\end{array}$ & $\begin{array}{c}\text { Surface } \\
\text { of } \\
\text { shoppin } \\
\text { g malls? }\end{array}$ & $\begin{array}{l}\text { Number } \\
\text { restaurants } \\
\text { and bars }\end{array}$ & $\begin{array}{c}\text { Retail } \\
\text { sales } \\
\text { index??? }\end{array}$ & $\begin{array}{l}\text { Index of } \\
\text { restaurants } \\
\text { and bars }\end{array}$ & $\begin{array}{l}\text { Tourist } \\
\text { index }\end{array}$ & $\begin{array}{l}\text { Cash } \\
\& \\
\text { Carry }\end{array}$ & $\begin{array}{l}\text { Surfac } \\
\text { e } \\
\text { Cash } \\
\& \\
\text { Carry }\end{array}$ & $\begin{array}{l}\text { Hyper- } \\
\text { markets }\end{array}$ & $\begin{array}{l}\text { Surfac } \\
\text { e of } \\
\text { Hyper } \\
\text { marke } \\
\text { ts??? }\end{array}$ & $\begin{array}{l}\text { Hypermarkets } \\
\text { larger than } \\
1000 \mathrm{~m}^{2}\end{array}$ & 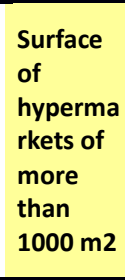 \\
\hline Alt Penedès & 26 & 2 & 2 & 2 & 2 & 2 & 0 & 0 & 2 & 2 & 2 & 4 & 1 & 1 & 2 & 2 & 2 & 2 \\
\hline Bages & 35 & 2 & 1 & 1 & 1 & 2 & 1 & 1 & 1 & 1 & 1 & 3 & 2 & 2 & 2 & 2 & 2 & 2 \\
\hline $\begin{array}{l}\text { Baix } \\
\text { Llobregat }\end{array}$ & 30 & 20 & 2 & 1 & 2 & 2 & 8 & 5 & 3 & 3 & 3 & 4 & 3 & 3 & 6 & 4 & 2 & 2 \\
\hline Barcelonès & 5 & 5 & 2 & 1 & 1 & 1 & 1 & 3 & 1 & 1 & 1 & 1 & 2 & 3 & 4 & 4 & 1 & 1 \\
\hline Berguedà & 30 & 1 & 3 & 4 & 2 & 1 & 0 & 0 & 1 & 3 & 1 & 3 & 1 & 1 & 0 & 0 & 1 & 1 \\
\hline Garraf & 6 & 4 & 3 & 3 & 3 & 1 & 1 & 1 & 3 & 3 & 3 & 2 & 1 & 1 & 1 & 1 & 4 & 4 \\
\hline Maresme & 29 & 13 & 1 & 1 & 1 & 1 & 3 & 2 & 1 & 1 & 1 & 4 & 3 & 3 & 4 & 4 & 1 & 2 \\
\hline Osona & 49 & 3 & 2 & 2 & 3 & 2 & 0 & 0 & 2 & 2 & 2 & 2 & 1 & 1 & 2 & 2 & 2 & 3 \\
\hline Selva & 1 & 0 & 1 & 0 & 1 & 1 & 0 & 0 & 1 & 1 & 0 & 0 & 0 & 0 & 0 & 0 & 0 & 0 \\
\hline Solsonès & 1 & 0 & 1 & 1 & 1 & 1 & 0 & 0 & 1 & 1 & 1 & 0 & 0 & 0 & 0 & 0 & 0 & 0 \\
\hline $\begin{array}{l}\text { Vallès } \\
\text { Occidental }\end{array}$ & 23 & 14 & 2 & 2 & 2 & 3 & 6 & 4 & 2 & 2 & 2 & 3 & 5 & 3 & 5 & 4 & 3 & 3 \\
\hline $\begin{array}{l}\text { Vallès } \\
\text { Oriental }\end{array}$ & 43 & 13 & 2 & 2 & 2 & 2 & 2 & 2 & 2 & 2 & 2 & 3 & 1 & 1 & 2 & 2 & 3 & 3 \\
\hline Total & 312 & 81 & 24 & 22 & 23 & 20 & 22 & 18 & 24 & 24 & 21 & 31 & 21 & 20 & 29 & 26 & 25 & 27 \\
\hline
\end{tabular}

Source: Based on data drawn from the Economic Yearbook of Spain and the Yearbook of Distribution in Spain. 
Table 4.4. Classification of header municipalities. Comarcal analysis. Alt Penedès

\begin{tabular}{|c|c|c|c|c|c|}
\hline Comarca & Municipality & $\begin{array}{l}\text { socioeconomic } \\
\text { criteria }\end{array}$ & $\begin{array}{c}\text { Tourist } \\
\text { products }\end{array}$ & $\begin{array}{l}\text { Weekday } \\
\text { head } \\
\text { municipali } \\
\text { ty }\end{array}$ & $\begin{array}{c}\text { Holiday/weeke } \\
\text { nd head } \\
\text { municipality }\end{array}$ \\
\hline & Vilafranca del Penedès & 20 & 41 & $x$ & $x$ \\
\hline & Sant Sadurní d'Anoia & 13 & 32 & $x$ & $x$ \\
\hline & Olèrdola & 8 & 15 & $x$ & $x$ \\
\hline & Santa Margarida i els & & & & \\
\hline & Monjos & 2 & 6 & $\mathrm{x}$ & $\mathrm{x}$ \\
\hline & Subirats & 2 & 29 & & $\mathrm{x}$ \\
\hline & Avinyonet del Penedès & 1 & 9 & & $\mathrm{x}$ \\
\hline & Castellet i la Gornal & 1 & 6 & & $\mathrm{x}$ \\
\hline & Castellví de la Marca & 1 & 6 & & \\
\hline & Font-rubí & 1 & 11 & & $x$ \\
\hline \multirow[t]{11}{*}{ Alt Penedès } & Gelida & 1 & 4 & $x$ & $x$ \\
\hline & Granada (La) & 1 & 2 & & \\
\hline & Mediona & 1 & 4 & & \\
\hline & Olesa de Bonesvalls & 1 & 1 & & \\
\hline & Pla del Penedès (El) & 1 & 3 & & \\
\hline & Sant Martí Sarroca & 1 & 6 & & $x$ \\
\hline & Sant Pere de Riudebitlles & 1 & 0 & & \\
\hline & Sant Quintí de Mediona & 1 & 3 & & \\
\hline & Torrelavit & 1 & 7 & & $x$ \\
\hline & Torrelles de Foix & 1 & 2 & & \\
\hline & Vilobí del Penedès & 1 & 10 & & $\mathrm{x}$ \\
\hline
\end{tabular}

Source: Own Elaboration. 
Maps 4.1 and 4.2: Urban Systems of Vilafranca del Penedès and Sant Sadurní d'Anoia

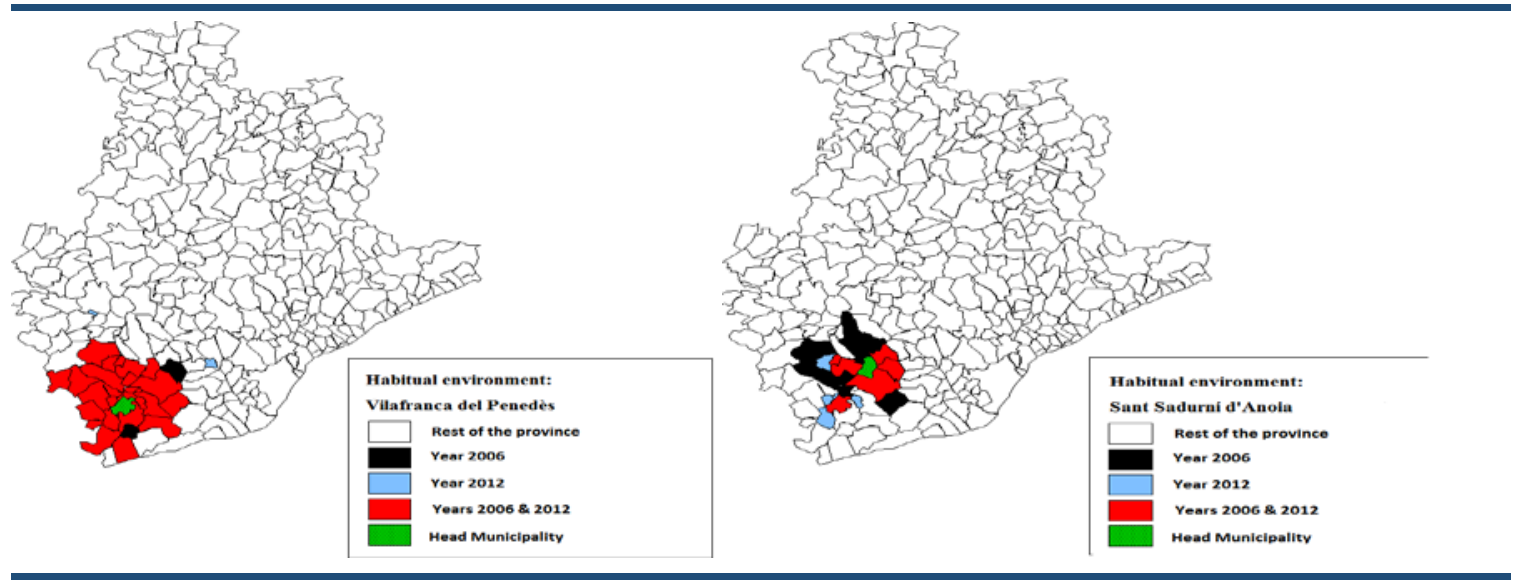

Map 4.3 and 4.4: Urban Systems of Olèrdola and d'Avinyonet del Penedès

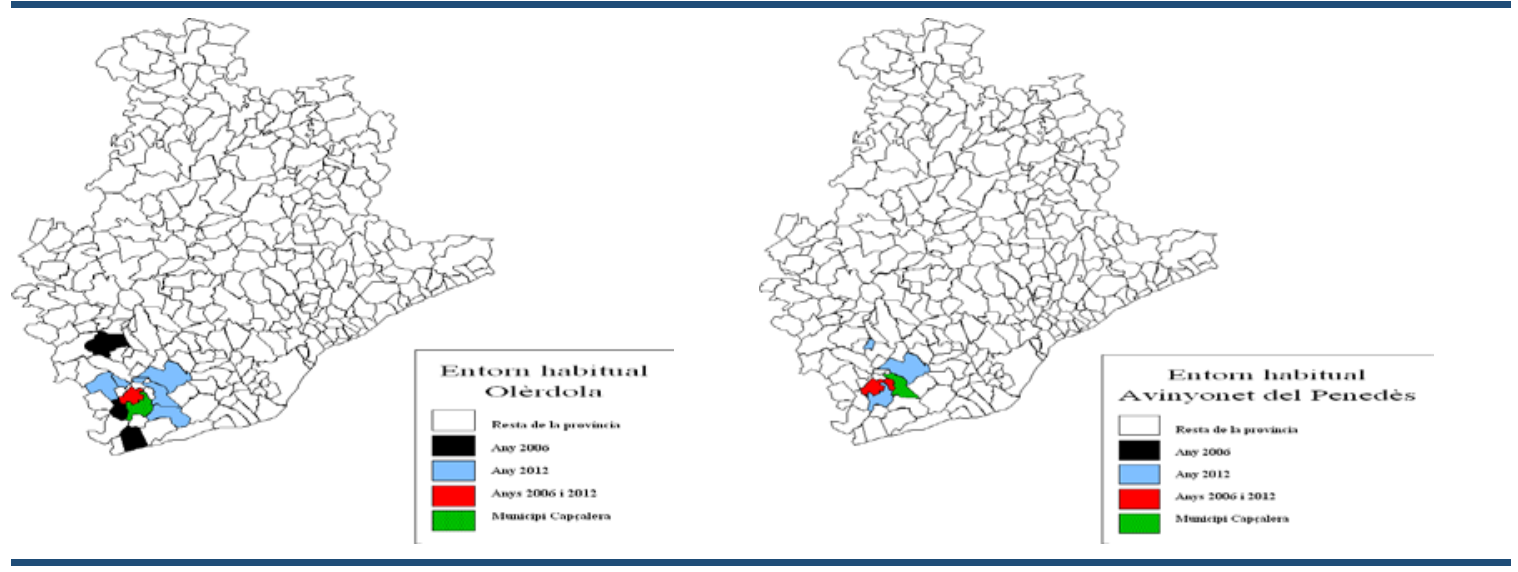

Map 4.5 and 4.6: Urban Systems of Castellet i la Gornal and Gelida

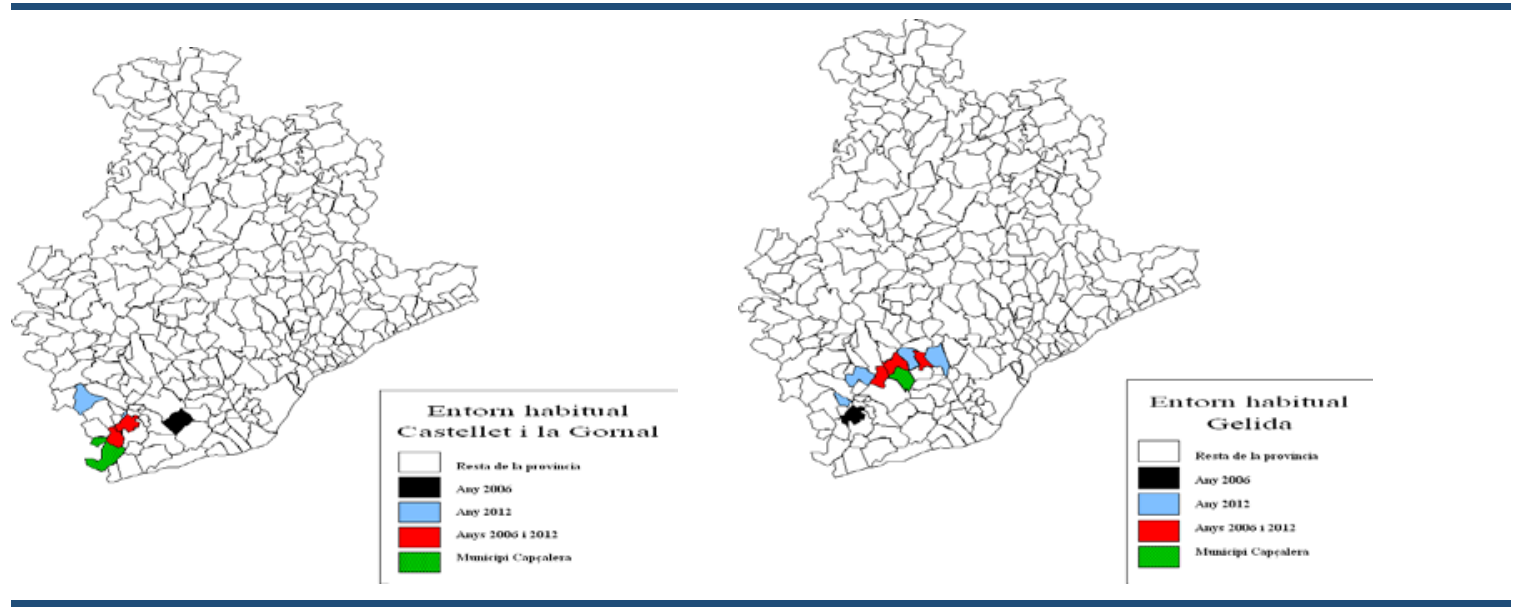


Map 4.7 and 4.8: Urban Systems of Sant Martí Sarroca and Santa Margarida i els Monjos

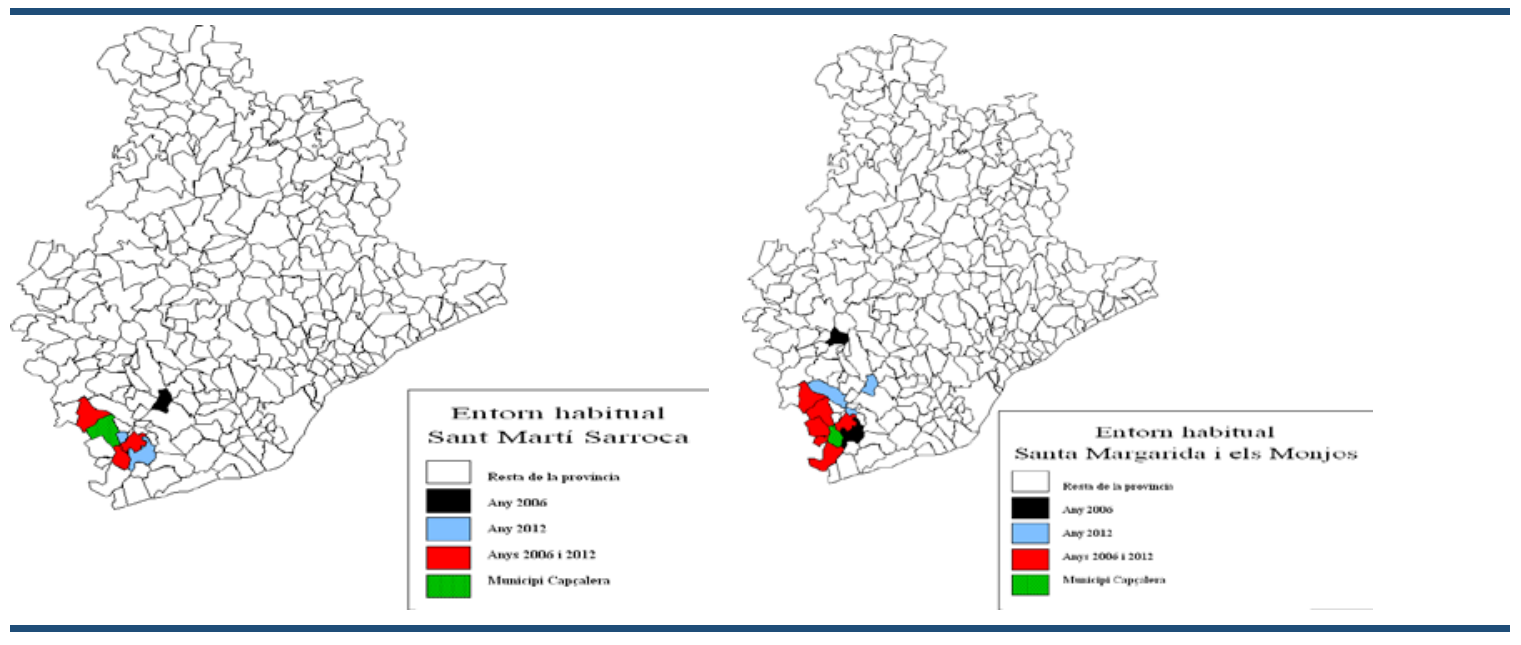

